\title{
The Correlation between Gender Inequalities and Their Health Related Factors in World Countries: A Global Cross-Sectional Study
}

\author{
Jafar Hassanzadeh, ${ }^{1}$ Noorollah Moradi, ${ }^{2}$ Nader Esmailnasab, ${ }^{3}$ Shahab Rezaeian, ${ }^{4}$ \\ Pezhman Bagheri, ${ }^{2}$ and Vajihe Armanmehr ${ }^{2}$ \\ ${ }^{1}$ Department of Epidemiology, School of Health, Shiraz University of Medical Sciences, P.O. Box 71645-111, Shiraz, Iran \\ ${ }^{2}$ Social Development and Health Promotion Research Center, Gonabad University of Medical Sciences, P.O. Box 397, Gonabad, Iran \\ ${ }^{3}$ Kurdistan Research Center for Social Determinants of Health (KRCSDH), School of Medicine, Kurdistan University of \\ Medical Sciences, P.O. Box 6618634683, Sanandaj, Iran \\ ${ }^{4}$ Health Promotion Research Center, Zahedan University of Medical Sciences, P.O. Box 98135, Zahedan, Iran
}

Correspondence should be addressed to Shahab Rezaeian; shahab.rezayan@gmail.com

Received 27 August 2014; Revised 19 October 2014; Accepted 20 October 2014; Published 9 November 2014

Academic Editor: Jaume Marrugat

\begin{abstract}
Copyright (C) 2014 Jafar Hassanzadeh et al. This is an open access article distributed under the Creative Commons Attribution License, which permits unrestricted use, distribution, and reproduction in any medium, provided the original work is properly cited.

The study aimed to investigate gender inequalities and their health associated factors in world countries. A cross-sectional survey was undertaken using data of United Nations Development Programme (UNDP) and World Health Organization (WHO). The main variable in this study was gender inequality index (GII). All countries were stratified by WHO regions. Pearson correlation coefficient was used to assess the linear correlation between GII and investigated factors by WHO regions. The mean of GII was greater in Africa and lower in Europe region. There was negative significant association between GII and life expectancy at birth and mean years of schooling, prevalence of current tobacco smoking, high blood pressure and overweight and obesity, alcohol consumption rate, and cancer death rate. But there was positive significant association between GII and noncommunicable diseases death rates. In conclusion, gender inequalities, though decreasing over the past decades in world, remain notably greater in Africa and Eastern Mediterranean regions than in Europe. Gender inequality is also an important issue which is related to health factors. Hence, countries will need to focus on public health intervention and equal distribution of economic resources to reduce gender inequality in society.
\end{abstract}

\section{Introduction}

Gender is a range of characteristics, roles, and behaviour patterns. The term gender distinguishes women from men socially and culturally and relations of power between them [1]. Gender affects most of the known factors related to health, including education, income, occupation, social networks, physical and social environments, and health services. Accordingly, gender has a significant influence on health and well-being throughout life [2-4].

Achieving gender equality is one of the leading millennium development health goals [5]. In developed countries, for example, Canada, efforts to promote gender equality in education and employment have been numerous [6], but many developing countries exhibit considerable gender inequality in education [7], employment [8], and health outcomes [9]. For example, there are large discrepancies in employment status between the sexes in black South African adults [8]. In addition, rural Chinese women have a significantly lower educational level than men [10]. While gender differences in health, assessed in terms of mortality and morbidity, have been reported in most developed countries over recent decades [11], less attention has been paid to the pattern of health care services use.

According to previous evidence, gender differences are reported in health and health care utilization, as women 
experience poorer health than men [12-14]. But some studies have investigated that, after controlling for health outcomes, women have higher utilization rates of medical services than men [15-17]. Numerous studies in the literature have reported that determinants of gender differences include welfare indicators (e.g., education and income) and behavioural (e.g., smoking and drinking) and social factors (e.g., social support and socioeconomic status) [18-20].

Although previous studies reported that global gender inequality is declining $[21,22]$, gender inequity in health still exists even in developed countries [23, 24]. Therefore, our purpose in this study was to investigate gender inequalities and their associated factors in world countries.

\section{Materials and Methods}

In this cross-sectional study, which was performed in 2013, we used dataset regarding International Human Development Indicators including gender inequality index (GII), life expectancy at birth, mean years of schooling and income in all countries worldwide reported by United Nations Development Programme (UNDP) [25]. The main variable in our study was gender inequality index. From the data, 54 countries were excluded because of missing observations in some variables especially gender inequality index. Hence, 139 countries remained for analysis. According to the UNDP report [26], gender inequality index is a new index for measurement of gender disparity. The value of GII ranges between 0 and 1 , with 0 being $0 \%$ inequality, indicating that women fare equally in comparison to men, and 1 being $100 \%$ inequality, indicating that women fare poorly in comparison to men. There are five steps for computing the GII [27]. The GII can be calculated as follows:

$$
\mathrm{GII}=1-\frac{\operatorname{Harm}\left(G_{F}, G_{M}\right)}{G_{\bar{F}, \bar{M}}},
$$

where Harm $\left(G_{F}, G_{M}\right)$ represents the harmonic mean to create the equally distributed gender index and $G_{\bar{F}, \bar{M}}$ represents the geometric mean of the arithmetic means for related indicator.

The continuous independent variables including noncommunicable disease (NCD) death rates, prevalence of current tobacco smoking, high blood pressure and body mass index greater than 25 , alcohol consumption rate, and cancer death rate used in the present study were estimated by World Health Organization (WHO) using standard methods to maximize cross-country comparability [28].

The explanation of indicators that were used by WHO is as follows: age-standardized death rate for NCDs per 100000 individuals and age-standardized death rate for cancers, prevalence of current daily tobacco smoking among adults (\%), adult per capita consumption in liters of pure alcohol, prevalence of raised blood pressure among adults (defined as systolic blood pressure $\geq 140 \mathrm{mmHg}$ and/or diastolic blood pressure $\geq 90 \mathrm{mmHg}$ or on medication for raised blood pressure (\%)), and prevalence of overweight and obesity in adults and adolescents (defined as body mass index greater
TABLE 1: The list of ten countries with the highest and the lowest gender inequality index by WHO regions.

\begin{tabular}{lcc}
\hline Country & Region & $\begin{array}{c}\text { Gender } \\
\text { inequality }\end{array}$ \\
\hline Iraq & Eastern Mediterranean & 0.803 \\
Yemen & Eastern Mediterranean & 0.791 \\
Niger & Africa & 0.737 \\
Mali & Africa & 0.722 \\
Democratic Republic of & Africa & 0.722 \\
the Congo & Africa & 0.718 \\
Mauritania & Eastern Mediterranean & 0.709 \\
Afghanistan & Eastern Mediterranean & 0.682 \\
Saudi Arabia & Western Pacific & 0.682 \\
Papua New Guinea & Africa & 0.679 \\
Central African Republic & Europe & 0.065 \\
Sweden & Europe & 0.068 \\
Denmark & Europe & 0.077 \\
Netherlands & Europe & 0.083 \\
Norway & Europe & 0.084 \\
Switzerland & Europe & 0.102 \\
Finland & Europe & 0.105 \\
Germany & Western Pacific & 0.118 \\
Republic of Korea & Europe & 0.118 \\
Spain & Europe & 0.121 \\
Iceland & &
\end{tabular}

than $25 \mathrm{~kg} / \mathrm{m}^{2}$ for overweight or $30 \mathrm{~kg} / \mathrm{m}^{2}$ for obesity or for adolescents).

All countries were stratified by $\mathrm{WHO}$ regions. The first analysis undertaken was to determine mean of GII, life expectancy at birth, and education (years) among WHO regions. Pearson correlation coefficient was used to assess the linear correlation between GII and life expectancy at birth and mean years of schooling and income. In addition, correlation between GII and other continuous variables was also assessed. Comparisons among WHO regions (Africa, Americas, Eastern Mediterranean, Europe, South East Asia, and Western Pacific) were done with One way ANOVA (Bonferroni test as post hoc). Comparisons, among gender groups for the mean of continuous variables, were done with the $t$-test.

All analyses were conducted at 95\% significant level using statistical software STATA 11 (StataCorp, College Station, Texas).

\section{Results}

The list of ten countries with the highest and the lowest gender inequality index by WHO regions was illustrated in Table 1. Half of the countries with the highest index of GI were African and the majority of countries with the lowest gender inequality index were European.

Table 2 summarizes the mean of gender inequality index, life expectancy at birth, and education (years) by WHO 
TABLE 2: The mean of gender inequality index, life expectancy at birth, and education (years) by WHO regions.

\begin{tabular}{lccc}
\hline WHO regions & $\begin{array}{c}\text { Gender inequality } \\
\text { Mean [95\% CI] }\end{array}$ & $\begin{array}{c}\text { Education } \\
\text { Mean [95\% CI] }\end{array}$ & $\begin{array}{c}\text { Life expectancy at birth } \\
\text { Mean [95\% CI] }\end{array}$ \\
\hline Africa & $0.61[0.58,0.64]$ & $5.01[4.27,5.75]$ & $55.63[53.39,57.88]$ \\
America & $0.45[0.41,0.48]$ & $8.29[7.62,8.96]$ & $74.31[72.80,75.81]$ \\
Eastern Mediterranean & $0.56[0.48,0.63]$ & $6.14[5.09,7.19]$ & $70.45[66.88,74.02]$ \\
Europe & $0.23[0.19,0.27]$ & $10.60[10.25,10.96]$ & $76.79[75.35,78.22]$ \\
South East Asia & $0.52[0.43,0.61]$ & $5.54[4.34,6.75]$ & $71.19[68.11,74.26]$ \\
Western Pacific & $0.33[0.23,0.42]$ & $8.69[7.20,10.18]$ & $73.60[69.84,77.36]$ \\
Total & $0.42[0.39,0.46]$ & $7.89[7.41,8.37]$ & $70.08[68.43,71.74]$ \\
\hline
\end{tabular}

regions. Overall, the mean of GII, mean year of schooling of adults, and life expectancy at birth in all countries worldwide were 0.42 [95\% CI: $0.39,0.46$ ], 7.89 ( \pm 2.98 years), and 70.08 ( \pm 9.64 years), respectively. As shown in Table 2 , the highest mean of life expectancy at birth and education is related to Europe region and the lowest mean of them is related to Africa region. The mean of GII in Europe region was significantly lower than in South East Asia and Western Pacific regions ( $P=0.003$ for both comparisons). The distribution of GII in world countries is shown in Figure 1.

According to the results of Table 4, in all WHO regions, GII was strongly and significantly associated with life expectancy at birth and mean years of schooling. Furthermore, there was also negative significant association between GII and income in all WHO regions except in Eastern Mediterranean region.

The Pearson's correlation among these variables (gender inequality index and NCD death rates, prevalence of current tobacco smoking, high blood pressure and body mass index greater than 25, alcohol consumption rate, and cancer death rate) was presented in Table 4 . There were negative significant associations between GII and these variables $(P<0.001$ for all relation). The GII was highly correlated to NCD death rates $(r=0.54, P<0.001)$.

The NCD death rates, prevalence of current tobacco smoking, high blood pressure and body mass index greater than 25 , alcohol consumption rate, and cancer death rate by WHO regions and gender were summarized in Table 3. As shown in Table 3, in total, there were significant differences in raised blood pressure (42.47) and current tobacco smoking prevalence between men and women $(P<0.001$ for both comparisons).

\section{Discussion}

The present study demonstrates the first comprehensive global-based estimates of gender inequality index and its health related factors in world countries including descriptive findings which resulted from UNDP and WHO reports [25, 28]. One of the major findings from this study is that the mean of GII is greater among Africa than among other WHO regions in worldwide. Generally, gender inequalities in worldwide may be explained by the differences between women and men in employment status, healthy life years,

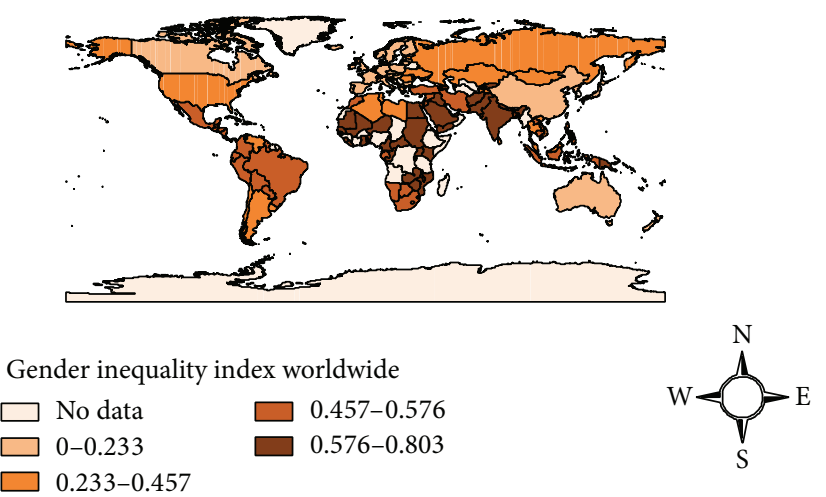

FIGURE 1: Distribution of gender inequality index worldwide, 2011.

income, lifestyles, and use of health care services $[10,14,17$, 29].

Our results showed that there was a negative significant relation between the GII and life expectancy at birth, in accordance with results of previous studies. Women live longer in nearly all countries worldwide. On the other hand, life expectancy in women is higher than in men [30,31]. According to van Oyen et al. study, the gender gap in life expectancy was restricted during the last decades of the twentieth century in most but not all European countries [32]. In addition, McCartney et al. reported that gender differences in mortality are dependent on modifiable lifestyle factors. For example, smoking has been considered one of the main causes of the gender difference in mortality across Europe [19].

Our study demonstrates disparities in the mean of schooling among world countries. Furthermore, there was a negative significant relationship between GII and education. The existence of education differentials among women and men has been well established [10, 29]. Also women have a lower social position as a result of a lower education and this may affect the gender difference in health among world countries. This result is consistent with results of previous investigations [33].

Little has been done to estimate gender inequalities in their related factors such as NCD mortality, education, and welfare indicators, particularly in low or middle income countries. Our results clearly show that, overall, there is correlation between GII and NCD mortality rate, prevalence 


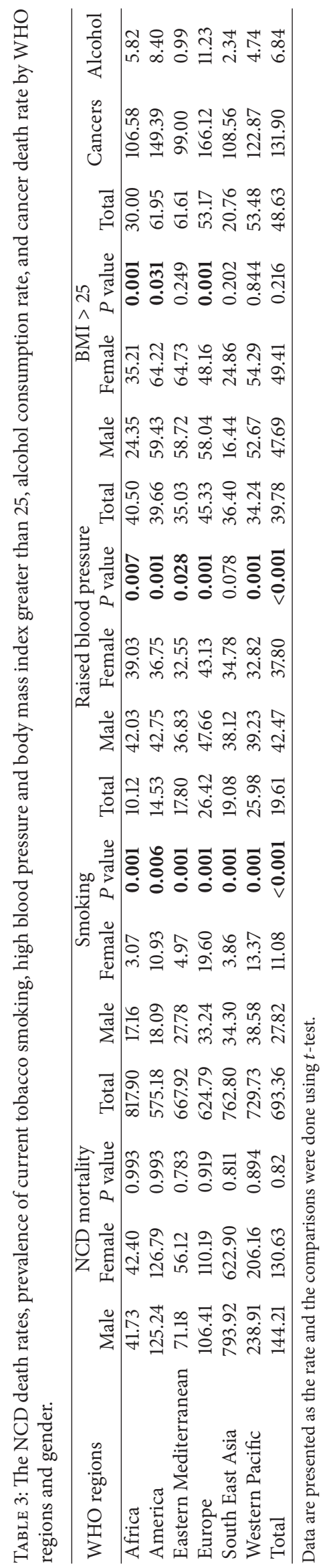




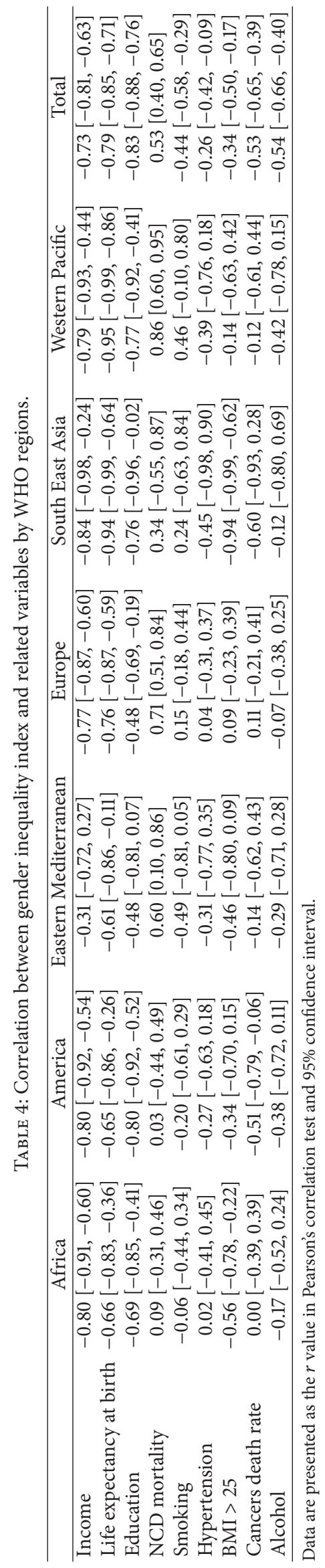


of current tobacco smoking, high blood pressure and body mass index greater than 25 , alcohol consumption rate, and cancer death rate. But there was no significant correlation between GII and these variables among WHO regions. It is possible that the small number of countries in subgroups by WHO regions in this study might have influenced our results.

Alcohol drinking is one of the major public health concerns worldwide and gender differences in roles and other behavior patterns are one important context for understanding alcohol problems. The results of present study showed that GII was negatively associated with alcohol consumption rate $(r=-0.53, P<0.001)$. In these analyses by income groups, GII was negatively associated with alcohol consumption rate among countries with high income and upper middle income $(P<0.001)$. This finding is consistent with a study that explored the association between gender differences and macrolevel across 25 European countries [32]. In that study, gender differences were positively associated with income inequality. In addition, we tested for a correlation between income and change in gender inequality index across countries and found a negative and consistent correlation $(r=-0.74, P<0.001)$. This finding is inconsistent with other assertions [21, 34].

Interestingly, there was a significant positive correlation between GII and NCD mortality rate while mean of NCD mortality rate did not have significant differences between men and women (97.6 versus 89.2 per 100,000, resp.). The World Health Organization reports mortality rates from NCD for men and women around the world [28]. The ratio of these rates in men and women is generally between 1 and 2. Why are NCD rates higher in men than in women? Stevens et al. indicated that the two main causes of death are cardiovascular diseases and cancers and they found both to be higher in men [35]. Besides, they reported that agestandardized NCD mortality rates are always higher for men than for women, except for diabetes. Our findings have also shown that risk factors of NCD such as raised blood pressure and smoking prevalence are higher in men than in women.

The health risks incurred by smoking are well documented, and men are more likely to smoke than women [36], although the gender gap has been closing over time and among adolescents is essentially nonexistent [37]. Among WHO regions, prevalence of current tobacco smoking is lowest for Africa region and significantly higher for Europe and Western Pacific regions. The prevalence of current tobacco smoking was found to be higher in males. Similar to our findings, previous studies also found that female gender is to be more common in light smokers [38]. Surprisingly, there was a negative significant correlation between GII and prevalence of current tobacco smoking both in whole and in subgroup by gender (Table 3 ).

Totally, raised blood pressure prevalence was negatively associated with increasing GII $(r=-0.26, P=0.002)$. This correlation was not significant by WHO regions. In many countries, hypertension is the number one risk factor for noncommunicable diseases and is a common, important, and major global public health problem $[39,40]$. In many of the studies inconsistent with our study, the prevalence of hypertension was higher in men than in women [41, 42].
Unlike most of other studies, we found that men had higher raised blood pressure prevalence than women (42.47 versus $37.80, P<0.001)$.

Some limitations and strengths of present study deserve consideration. Data for GII and its related factors were collected based on UNDP and WHO reports, allowing for comparisons of standardized data across pooled data sets. Consistent definitions in these data facilitated comparisons across several countries and WHO regions, minimizing limitations associated with sample size and selection and information bias. Although the use of pooled data from geographically and culturally diverse settings inevitably masks problems of comparability between countries, there probably is Simpson's paradox.

\section{Conclusion}

In conclusion, gender inequalities, though decreasing over the past decades in world, remain notably greater in Africa and Eastern Mediterranean regions than in Europe. Gender inequality is also an important issue which is related to health factors. Countries will need to focus on public health intervention and equal distribution of economic resources to reduce gender inequality in society. This cross sectional study is the first to assess the factors associated with gender inequality index using global data among World Health Organization regions. These results need to be confirmed in large epidemiological studies.

\section{Conflict of Interests}

The authors declare that there is no conflict of interests regarding the publication of this paper.

\section{Acknowledgments}

This paper is a part of M.S. thesis supported by University of Social Welfare and Rehabilitation Sciences. This paper uses data from the WHO and UNDP surveys.

\section{References}

[1] World Health Organization, "What do we mean by "sex" and "gender"?" 2010, http://www.who.int/gender/whatisgender/en/ index.html.

[2] S. G. Prus and E. Gee, "Gender differences in the influence of economic, lifestyle, and psychosocial factors on later-life health," Canadian Journal of Public Health, vol. 94, no. 4, pp. 306-309, 2003.

[3] M. Denton, S. Prus, and V. Walters, "Gender differences in health: a Canadian study of the psychosocial, structural and behavioural determinants of health," Social Science and Medicine, vol. 58, no. 12, pp. 2585-2600, 2004.

[4] S. Luchenski, A. Quesnel-Vallée, and J. Lynch, "Differences between women's and men's socioeconomic inequalities in health: longitudinal analysis of the Canadian population, 19942003," Journal of Epidemiology and Community Health, vol. 62, no. 12, pp. 1036-1044, 2008. 
[5] World Health Organization, Commission on Social Determinants of Health: Closing the Gap in a Generation: Health Equity Through Action on the Social Determinants of Health, Geneva, Switzerland, 2008.

[6] D. E. Stewart, L. M. Dorado, N. Diaz-Granados et al., "Examining gender equity in health policies in a low- (Peru), middle(Colombia), and high- (Canada) income country in the Americas," Journal of Public Health Policy, vol. 30, no. 4, pp. 439-454, 2009.

[7] H. van Nguyen and T. T. Giang, "Gender difference in academic planning activity among medical students," PLoS ONE, vol. 8, no. 2, Article ID e55845, 2013.

[8] A. Kruger, M. P. Wissing, G. W. Towers, and C. M. Doak, "Sex differences independent of other psycho-sociodemographic factors as a predictor of body mass index in black South African adults," Journal of Health, Population and Nutrition, vol. 30, no. 1, pp. 56-65, 2012.

[9] S. H. Wu, S. C. Ho, P. H. Chau, W. Goggins, A. Sham, and J. Woo, "Sex differences in stroke incidence and survival in Hong Kong, 2000-2007," Neuroepidemiology, vol. 38, no. 2, pp. 69-75, 2012.

[10] J. Wu, Y. Liu, K. Rao, Q. Sun, J. Qian, and Z. Li, "Educationrelated gender differences in health in rural China," American Journal of Public Health, vol. 94, no. 10, pp. 1713-1716, 2004.

[11] T. M. Miller, S. Gilligan, L. L. Herlache, and J. G. Regensteiner, "Sex differences in cardiovascular disease risk and exercise in type 2 diabetes," Journal of Investigative Medicine, vol. 60, no. 4 , pp. 664-670, 2012.

[12] H. Chun, Y.-H. Khang, I.-H. Kim, and S.-I. Cho, "Explaining gender differences in ill-health in South Korea: the roles of socio-structural, psychosocial, and behavioral factors," Social Science \& Medicine, vol. 67, no. 6, pp. 988-1001, 2008.

[13] A. A. Gerritsen and W. L. Devillé, "Gender differences in health and health care utilisation in various ethnic groups in the Netherlands: a cross-sectional study," BMC Public Health, vol. 9, article 109, 2009.

[14] H. Van Oyen, W. Nusselder, C. Jagger, P. Kolip, E. Cambois, and J.-M. Robine, "Gender differences in healthy life years within the EU: an exploration of the "health-survival" paradox," International Journal of Public Health, vol. 58, no. 1, pp. 143-155, 2013.

[15] C. Yoon, Y.-S. Ju, and C.-Y. Kim, "Disparities in health care utilization among urban homeless in South Korea: a crosssectional study," Journal of Preventive Medicine and Public Health, vol. 44, no. 6, pp. 267-274, 2011.

[16] K. H. Ladwig, B. Marten-Mittag, B. Formanek, and G. Dammann, "Gender differences of symptom reporting and medical health care utilization in the German population," European Journal of Epidemiology, vol. 16, no. 6, pp. 511-518, 2000.

[17] Á. Redondo-Sendino, P. Guallar-Castillón, J. R. Banegas, and F. Rodríguez-Artalejo, "Gender differences in the utilization of health-care services among the older adult population of Spain," BMC Public Health, vol. 6, article 155, 2006.

[18] A. R. Hosseinpoor, J. S. Williams, A. Amin et al., "Social determinants of self-reported health in women and men: understanding the role of gender in population health," PLoS ONE, vol. 7, no. 4, Article ID e34799, 2012.

[19] G. McCartney, L. Mahmood, A. H. Leyland, G. David Batty, and K. Hunt, "Contribution of smoking-related and alcoholrelated deaths to the gender gap in mortality: evidence from 30 European countries," Tobacco Control, vol. 20, no. 2, pp. 166-168, 2011.
[20] B. Goesling and D. P. Baker, "Three faces of international inequality," Research in Social Stratification and Mobility, vol. 26, no. 2, pp. 183-198, 2008.

[21] S. F. Dorius and G. Firebaugh, "Trends in global gender inequality," Social Forces, vol. 88, no. 5, pp. 1941-1968, 2010.

[22] P. Sandiford, "Getting back the missing men of Aotearoa: declining gender inequality in NZ life expectancy," Journal of Primary Health Care, vol. 1, no. 4, pp. 270-277, 2009.

[23] J. Hippisley-Cox, J. Yates, M. Pringle, C. Coupland, and V. Hammersley, "Sex inequalities in access to care for patients with diabetes in primary care: questionnaire survey," British Journal of General Practice, vol. 56, no. 526, pp. 342-348, 2006.

[24] R. Lawrenson, V. Gibbons, G. Joshy, and P. Choi, "Are there disparities in care in people with diabetes? A review of care provided in general practice," Journal of Primary Health Care, vol. 1, no. 3, pp. 177-183, 2009.

[25] United Nations Development Programme, "Country Profiles and International Human Development Indicators," 2011, http://hdr.undp.org/en/countries/.

[26] United Nations Development Programme, Human Development Report 2010; The Real Wealth of Nations, United Nations Development Programme, New York, NY, USA, 2010.

[27] S. Alkire, M. Friedman, G. R. Aguilar, S. Valenti, J. Tomkinson, and D. Zavaleta, "Training Material for Producing National Human Development Reports: The Gender Inequality Index (GII)," 2011, http://www.ophi.org.uk/wp-content/ uploads/OPHI-RP-28a.pdf-2011.pdf.

[28] World Health Organization, Global Status Report on Noncommunicable Diseases 2010, World Health Organization, Geneva, Switzerland, 2011.

[29] A. Zajacova and R. A. Hummer, "Gender differences in education effects on all-cause mortality for white and black adults in the United States," Social Science \& Medicine, vol. 69, no. 4, pp. 529-537, 2009.

[30] A. Barford, D. Dorling, G. D. Smith, and M. Shaw, "Life expectancy: women now on top everywhere," British Medical Journal, vol. 332, no. 7545, p. 808, 2006.

[31] M. E. Motlagh, R. Safari, M. Karami, and A. Khosravi, "Life expectancy at birth in rural areas based on corrected data of the Iranian vital horoscope," Iranian Journal of Public Health, vol. 41, no. 9, pp. 18-24, 2012.

[32] H. van Oyen, B. Cox, C. Jagger et al., "Gender gaps in life expectancy and expected years with activity limitations at age 50 in the European Union: associations with macro-level structural indicators," European Journal of Ageing, vol. 7, no. 4, pp. 229-237, 2010.

[33] C. E. Bird and P. P. Rieker, Gender and Health: The Effect of Constrained Choice and Social Policies, Cambridge University Press, Cambridge, UK, 2008.

[34] M. L. Chang, "The evolution of sex segregation regimes," The American Journal of Sociology, vol. 105, no. 6, pp. 1658-1701, 2000.

[35] A. Stevens, M. I. Schmidt, and B. B. Duncan, "Gender inequalities in non communicable disease mortality in Brazil," Ciencia e Saude Coletiva, vol. 17, no. 10, pp. 2627-2634, 2012.

[36] M. Waked, G. Khayat, and P. Salameh, "Cigarette smokers' profile in lebanese adults," Journal of Research in Health Sciences, vol. 12, no. 2, pp. 75-80, 2012.

[37] J. M. Wallace Jr., J. G. Bachman, P. M. O’Malley, J. E. Schulenberg, S. M. Cooper, and L. D. Johnston, "Gender and ethnic differences in smoking, drinking and illicit drug use 
among American 8th, 10th and 12th grade students, 1976-2000," Addiction, vol. 98, no. 2, pp. 225-234, 2003.

[38] B. Moeini, J. Poorolajal, and Z. G. Gharghani, "Prevalence of cigarette smoking and associated risk factors among adolescents in Hamadan city, west of Iran in 2010," Journal of Research in Health Sciences, vol. 12, no. 1, pp. 31-37, 2012.

[39] K. Wolf-Maier, R. S. Cooper, J. R. Banegas et al., "Hypertension prevalence and blood pressure levels in 6 European countries, Canada, and the United States," The Journal of the American Medical Association, vol. 289, no. 18, pp. 2363-2369, 2003.

[40] F. Alemseged, A. Haileamlak, A. Tegegn et al., "Risk factors for chronic non-communicable diseases at gilgel gibe field research center, southwest ethiopia: population based study," Ethiopian Journal of Health Sciences, vol. 22, no. S, pp. 19-28, 2012.

[41] O. S. Ogah, I. Okpechi, I. I. Chukwuonye et al., "Blood pressure, prevalence of hypertension and hypertension related complications in Nigerian Africans: a review," World Journal of Cardiology, vol. 4, no. 12, pp. 327-340, 2012.

[42] I. I. Ulasi, C. K. Ijoma, and O. D. Onodugo, "A communitybased study of hypertension and cardio-metabolic syndrome in semi-urban and rural communities in Nigeria," BMC Health Services Research, vol. 10, article 71, 2010. 


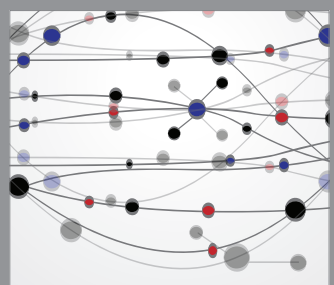

The Scientific World Journal
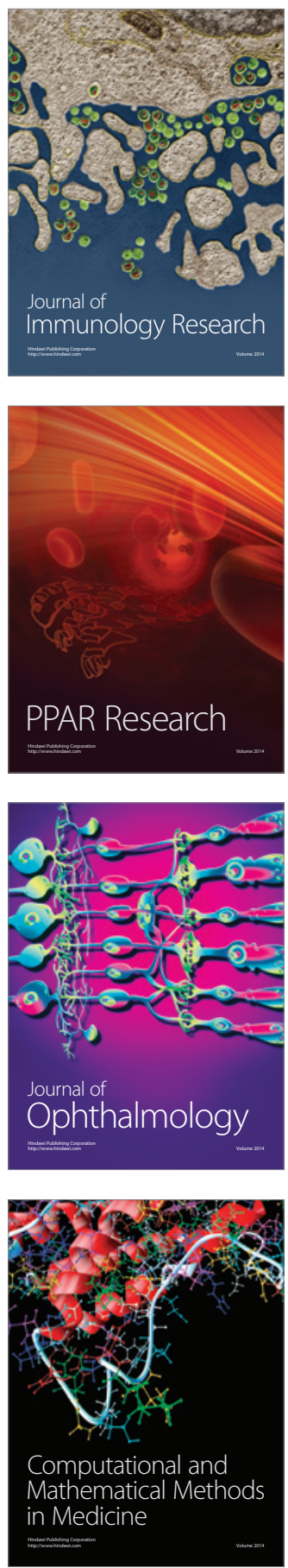

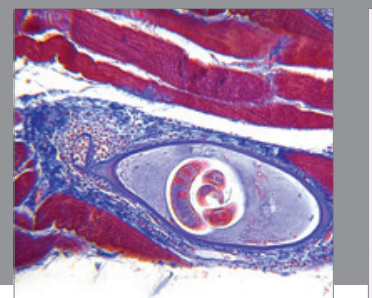

Gastroenterology

Research and Practice
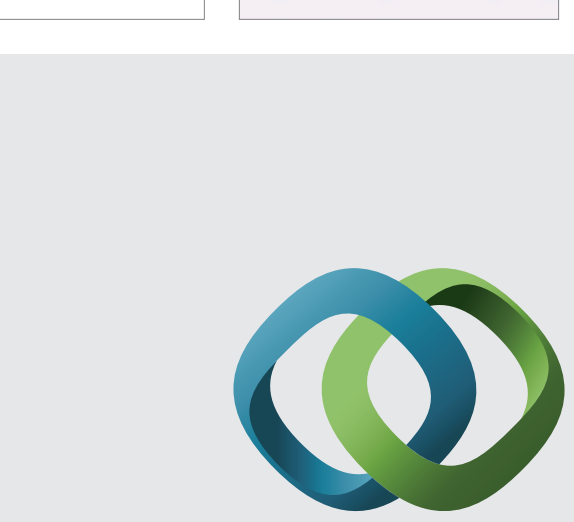

\section{Hindawi}

Submit your manuscripts at

http://www.hindawi.com
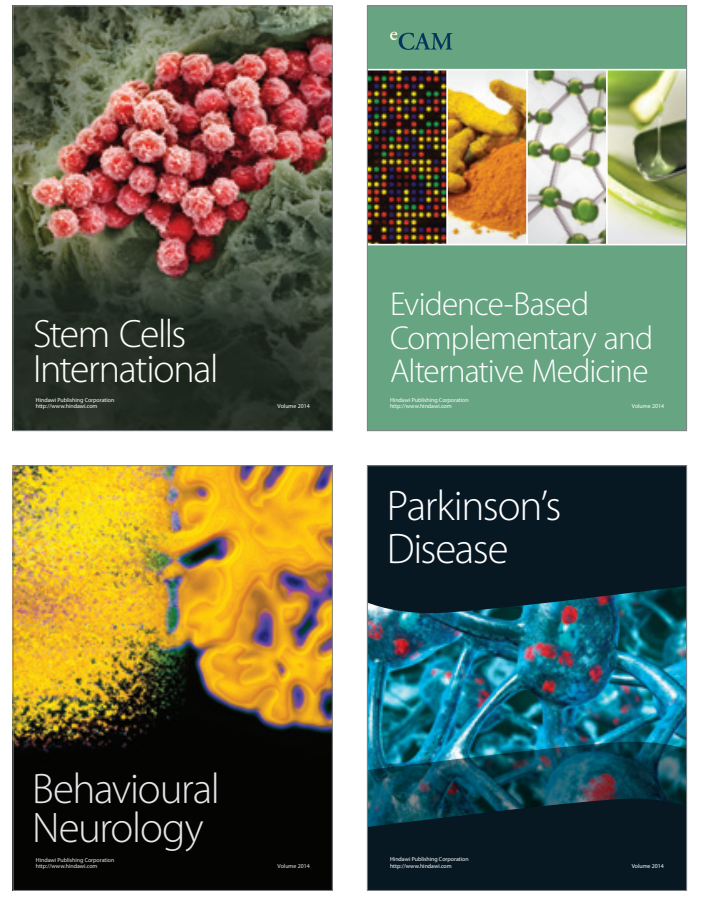
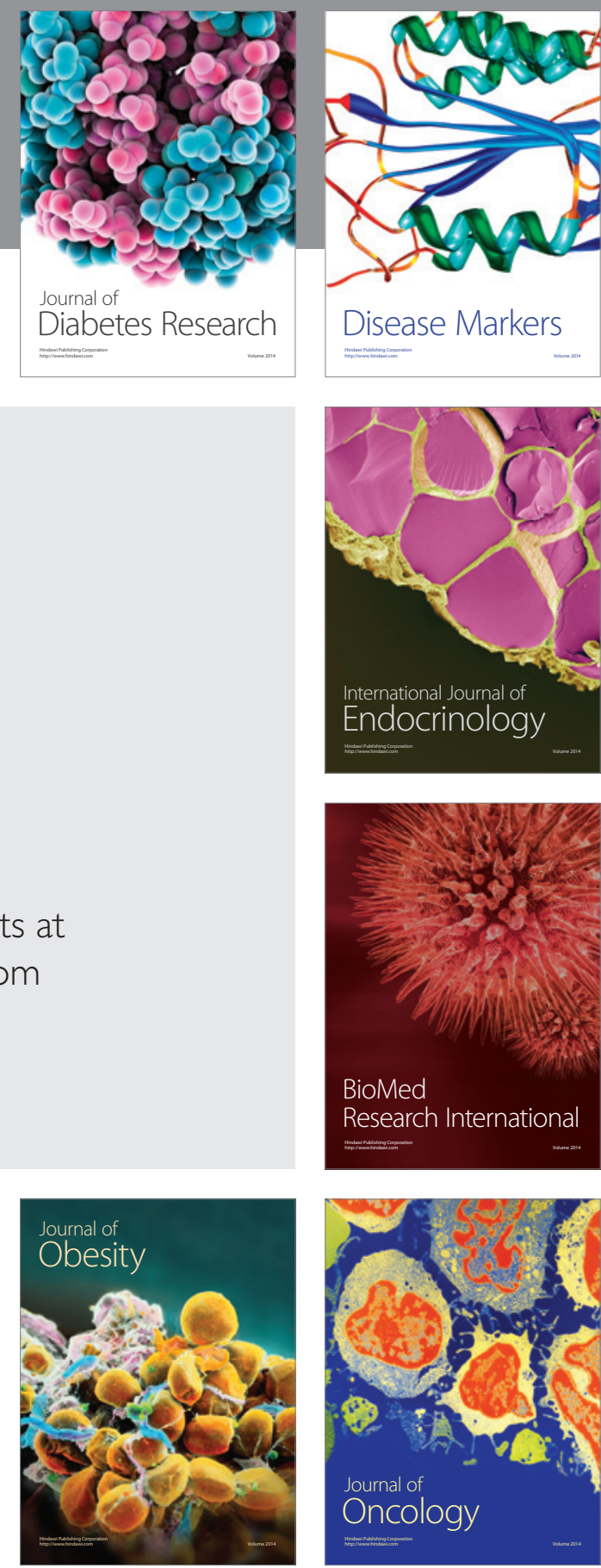

Disease Markers
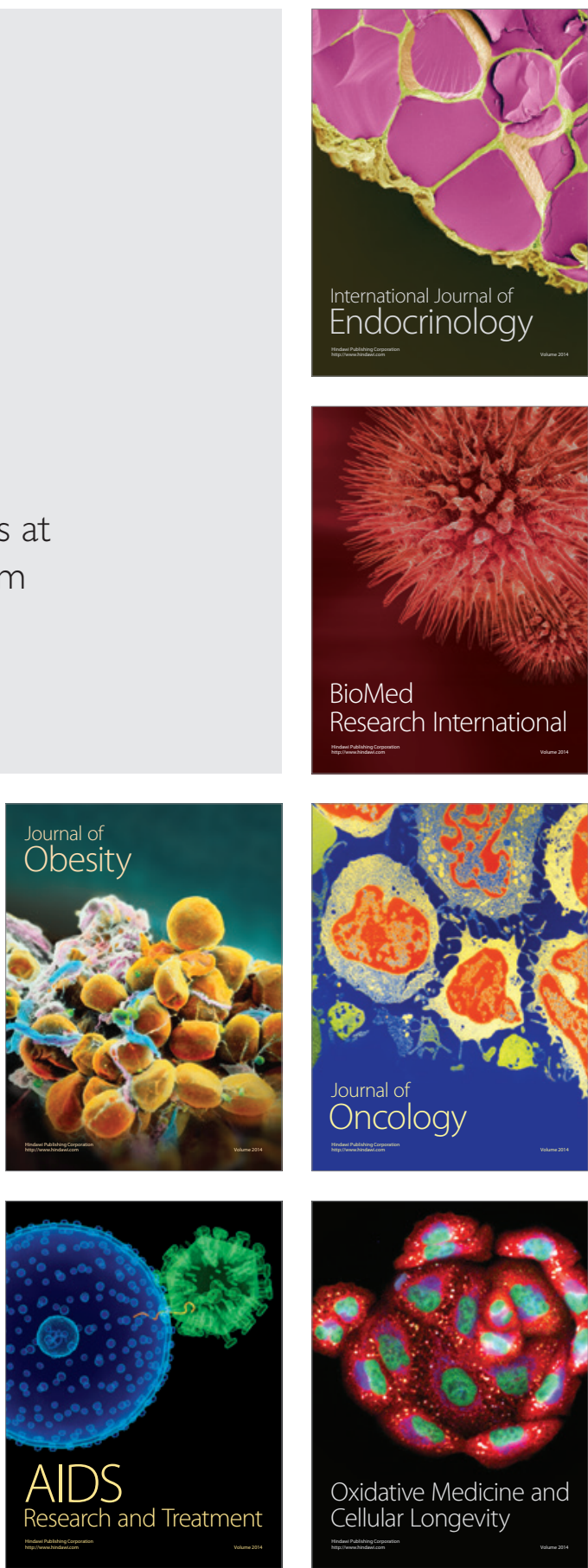